\title{
NÃO-PREFERÊNCIA PARA ALIMENTAÇÃO DE TRAÇA-DAS-CRUCÍFERAS POR GENÓTIPOS DE COUVE-FLOR
}

\section{A.L. Boiça Júnior; N.R. Chagas Filho}

UniversidadeEstadual Paulista, Faculdade deCiências Agráriase Veterinárias, DepartamentodeFitossanidade, Via de Acesso Prof. Paulo Donato Castellane, s/no, CEP 14884-900, Jaboticabal, SP, Brasil. E-mail: aboicajr@fcav.unesp.br

\section{RESUMO}

Avaliou-se a não-preferência alimentar de lagartas de Plutella xylostella (L.), pelos genótipos de couve-flor, híbridos Barcelona, Verona, Piracicaba Precoce, Sharon, SilverStreakecultivar Teresópolis Gigante. Foram realizados ensaios com e sem chance de escolha, em laboratório do Departamento de Fitossanidade da FCAV/UNESP, Jaboticabal, SP, avaliando-se o número de insetos atraídos e a massa seca consumida pelas lagartas do primeiroínstar (recém-eclodidas) e dequartoínstar durante24horas. Nos testes com e sem chance de escolha, para lagartas de primeiroequartoínstar, nãohouve diferença significativa quanto à atratividade. $O$ peso seco consumido verificado nos testes com e sem chance de escolha, para lagartas de primeiro e quarto ínstar, revelou diferença significativa entre os genótipos apenas no teste sem chance de escolha para lagartas de primeiro instar, destacando-se o híbrido Silver Streak como o mais consumido (3,72 mg) pelas lagartas de P.xylostella. Os genótipos de couve-flor testadosnãoinfluenciarama atratividadedaslagartas primeiroinstar(recém-eclodidas) equartoínstar e não apresentam resistência do tipo não-preferência para alimentação por lagartas de P.xylostella.

PALAVRAS-CHAVE: Plutella xylostella, Brassicaceae, tipos de resistências, Insecta.

\section{ABSTRACT}

FEEDING NONPREFERENCE OF DIAMONDBACK IN CAULIFLOWER GENOTYPES. The feeding nonpreference of Plutella xylostella (L.) larvae was tested in regard to the cauliflower genotypes Barcelona, Verona, Piracicaba Precoce, Sharon, Silver Streak (hybrids) and Teresópolis Gigante (cultivar). Choice and no-choice tests were carried out at the laboratories of the Departamento de Fitossanidade, FCAV/UNESP, Jaboticabal, state of São Paulo, Brazil, to study attractiveness and dry mass consumption by 1st-instar (just hatched) and 4th-instar larvae for 24 hours. No significant difference was found for attractiveness in choice and no-choice tests, for both 1st- and 4th-instar larvae. The consumption of dry mass in both tests, with 1st-and 4th-instar larvae, showed a significant difference between genotypes only for 1st-instar larvae, the hybrid Silver Streak being the most consumed $(3.72 \mathrm{mg})$ by P.xylostella larvae. The cauliflower genotypes tested presented no variation in attractiveness for 1st-instar (just hatched) and 4th-instar larvae and did not present nonpreference feeding resistance for $P$. xylostella larvae.

KEY WORDS: Plutella xylostella, Brassicaceae, resistance types, Insecta.

\section{INTRODUÇÃO}

As brássicas vêm ocupando um papel de destaque entre as hortaliças, não só pelo seu alto valor nutritivo devido ao fornecimento de vitaminas, cálcio, ferro e proteína (SANTOS, 2000), mas também pela grande expansão das agroindústrias de alimentos congelados, minimamente processados e conservas, dentre outras.

A couve-flor esta incluída entre as principais brássicas de consumo diário, apreciada em todo o mundo. No Brasil, é mais cultivada na região Sul e Sudeste. Atualmente, a utilização de híbridos mais adequados a regiões de clima quente e resistente a pragas e doenças tem facilitado seu cultivo durante o ano todo (Almeida, 2004).

Segundo Filgueira (1982), as principais pragas das brássicas são: Plutella xylostella (Linneaus, 1758) (traça-das-crucíferas), Trichoplusia ni (Hubner, 1803) (lagarta mede-palmo), Agrotis ipsilon (Hufnagel, 1766) (lagarta-rosca), Diabrotica speciosa (Germar, 1824) (vaquinha), Brevicoryne brassicae (Linneaus, 1758) (pulgão-da-couve) e Ascia monuste orseis (Godart, 1819) (curuquerê-da-couve).

A traça-das-crucíferas é uma praga que ocorre em todo o país e, dependendo da região e época de plantio, reduz consideravelmente o valor comercial 
do produto. Em couve-flor ataca as folhas centrais diminuindo a área fotossintética da planta, o que ocasiona a diminuição da produção deinflorescências. A severa infestação da traça-das-crucíferas ao longo do ciclo da cultura de couve-flor diminui a porcentagem de couve-flor comercializável (DiAs et al., 2002).

Como a cultura é principalmente utilizada por pequenos produtores, o uso de variedades resistentes representa uma alternativa que poderá não apenas reduzir as populações das pragas, mas também viabilizar sua produção, uma vez que diminui a quantidade de inseticidas e resíduos.

No presente trabalho objetivou-se verificar a presença do tipo de resistência não-preferência para alimentação de $P$. xylostella por genótipos de couveflor, em teste com e sem chance de escolha.

\section{MATERIAL E MÉTODOS}

O trabalho foi desenvolvido no laboratório de Resistência de Planta a Insetos situado no Departamento de Fitossanidade da FCAV/UNESP, Campus Jaboticabal, SP. As condições de laboratório utilizadas para a criação e condução dos experimentos foram: temperatura de $25 \pm 1^{\circ} \mathrm{C}$, umidade relativa 70 $\pm 10 \%$ e fotofase de 12 horas.

Para a realização dos experimentos foi mantida uma criação estoque de $P$. xylostella, utilizando-se insetos coletados inicialmente em culturas de crucíferas na região de Jaboticabal, adotando-se a metodologia proposta por TORRES (2004). Os adultos capturados foram confinados em gaiolas plásticas transparentes circulares, com uma abertura retangular lateral, vedada com malha fina de "nylon" possibilitandoa circulaçãodear. A parte superior da gaiola continha um orifício onde foi colocada uma esponja embebida com solução de mel a $10 \%$, presa com uma rolha de pano tamponando o orifício. Foram colocados discos de folhas de couve, Brassica oleracea L. var. acephala DC, cultivar Geórgia, medindo $8 \mathrm{~cm}$ de diâmetro sobre um copo plástico contendo papel de filtro umedecido em água destilada, onde as fêmeas realizaram a postura. Os discos foram substituídos diariamente e acondicionados em placas de Petri até a eclosão das lagartas. As lagartas recémeclodidas foram confinadas em recipientes plásticos comdimensões de $15 \mathrm{~cm} \times 10 \mathrm{~cm} \times 5 \mathrm{~cm}$, alimentadascom folhas de plantas decouve, cultivarGeórgia, previamente lavadas em água corrente. As folhas foram trocadas diariamenteatéquetodososinsetosatingissemafasede pupa. Essasforamcoletadaseacondicionadasemtubos de vidro de fundo chato medindo $1 \mathrm{~cm}$ de diâmetro, fechado com filme plástico transparente de "PVC" com pequenos orifícios para a circulação dear, para obtenção dos adultos. Para a condução dos experimentos foram semeadas sementes decouve-flor, B.oleracea var.botrytis, híbridos Barcelona, Verona, Piracicaba Precoce, Sharon, Silver Streak e da cultivar Teresópolis Gigante, em bandejas deisoporcontendosubstratoPlantmax ${ }^{\circledR}$ equando atingiram 30 dias de idade foram transplantadas para vasosde5Ldecapacidade,contendotrês partes deterra, uma deareia, uma de estercoe $1 / 4$ devermiculita eesses mantidos em casa de vegetação. Adotaram-se os tratos culturais para a cultura de acordo com CAMARGO (1992) e, sempre que necessário, foram efetuadas irrigações e quando as plantas de couve-flor atingiram 30 dias após o transplantio foram realizados os experimentos.

Nos testes com chance de escolha para estudar a orientação de lagarta do primeiro instar recémeclodidas e de quarto ínstar, utilizou-se uma arena constituída por uma placa de Petri, com diâmetro de $15 \mathrm{~cm}$, contendo papel de filtro levemente umedecido no fundo. Em cada placa colocou-se um disco foliar de $3 \mathrm{~cm}$ de diâmetro, de cada genótipo, dispostos equidistantes entre si e próximos da borda da placa. No experimento com lagartas de primeiro ínstar foram liberadas sete delas por genótipo e com as de quarto ínstar, três por genótipo.

As avaliações do número de lagartas em cada disco de folha para lagartas de primeiro ínstar foram feitas aos 10, 15 e 30 minutos e 1, 2, 3, 6, 12 e 24 horas e, para lagartas de quarto ínstar, foram feitas aos 1,3, $5,10,15$ e 30 minutos e 1, 2, 3, 6, 12 e 24 horas após a sua liberação..

Após 24 horas da liberação das lagartas ou assim que o primeiro disco apresentou um mínimo de $75 \%$ da sua área consumida, o experimento foi interrompido, retirando-se todos os insetos e procedendo-se a avaliação da massa seca consumida (LARA, 1991).

Para a avaliação da massa seca consumida da folha (disco) pelas lagartas, foi utilizado um disco de folha de cada genótipo, o qual foi seco em estufa a $40^{\circ} \mathrm{C}$ até massa constante, obtendo-se a massa seca da alíquota. Equidistante do local da retirada deste disco (alíquota) na folha foi retirado outro disco para ser oferecido às lagartas, obtendo-se após seco e pesado, a massa seca da sobra do disco após a alimentação das lagartas. A diferença obtida entre a alíquota e a sobra do disco consumido representou a massa seca consumida pelas lagartas em cada genótipo.

No teste sem chance de escolha, também com lagartas de primeiro instar recém-eclodidas e de quarto ínstar, colocou-se um único disco de folha de cada genótipo por placa de Petri, com $9 \mathrm{~cm}$ de diâmetro, contendo também papel de filtro levemente umedecido no fundo. No experimento com lagartas recémeclodidas foram liberadas sete lagartas por placa e com as de quarto ínstar três por placa.

As avaliações do número delagartas em cada disco de folha e da massa seca consumida pelas lagartas recém-eclodidas equartoínstaresforam semelhanteàs realizadas no teste com chance de escolha. 
Não-preferência para alimentação de traça-das-crucíferas por genótipos de couve-flor.

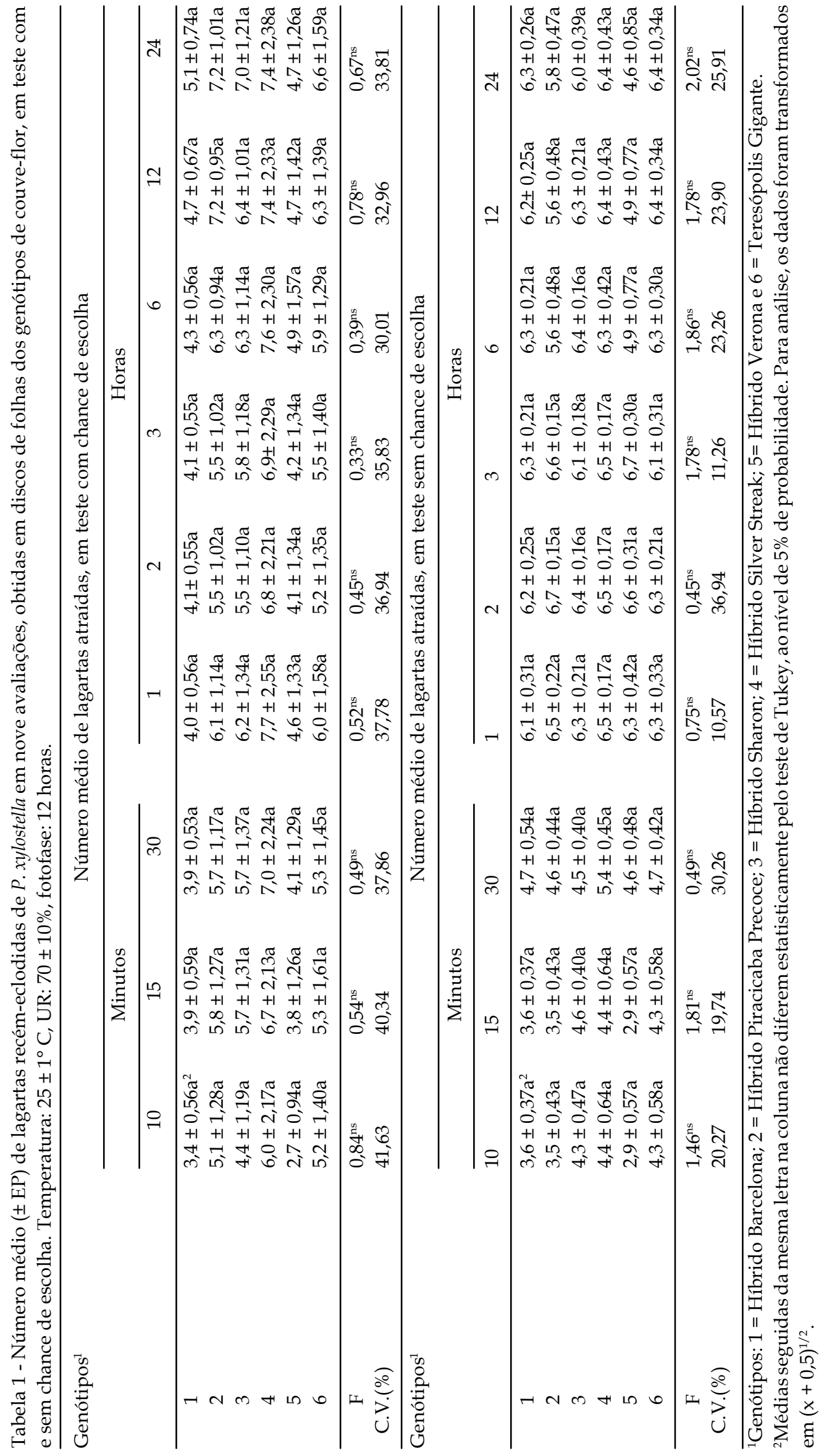


Em ambos os testes, o delineamento experimental utilizado foi inteiramente casualizado com seis tratamentos, híbridos Barcelona, Verona, Piracicaba Precoce, Sharon, Silver Streak e cultivar Teresópolis Gigantee10 repetições. Os resultados foram submetidos à análise de variância e as médias comparadas pelo teste de Tukey $(\alpha=0,05)$.

\section{RESULTADOS E DISCUSSÃO}

A atratividade das lagartas de P. xylostella pelos discos de folhas dos genótipos de couve-flor não diferiu entre si nos testes com e sem chance deescolha, para as lagartas de primeiro e quarto ínstar (Tabelas 1e2). A atratividade obtida a partir do total de lagartas no intervalo entre 10 a 30 minutos para lagartas de primeiro ínstar, no intervalo entre 1 a 30 minutos para lagartas de quarto ínstar, e a média das lagartas no intervalo entre 1 minuto e 24 horas, após a liberação das lagartas, também não diferiu significativamente nesses testes (Tabelas 2 e 4).

Apesar de não ter havido diferença nos testes, podesenotaruma tendência deuma maior atratividade de lagartas de primeiro ínstar pelos discos de folhas do híbrido Silver Streak nos testes com e sem chance de escolha (Tabelas 1 e 2), e para as lagartas de quarto ínstar pelos discos de folhas do híbrido Verona nos testes com chance de escolha (Tabelas 3 e 4). OliveIRA et al. (2004), trabalhando com A. monuste orseis, com os mesmos genótipos de couve-flor utilizados nos experimentos, verificaram que as lagartas têm uma maior atratividade pelo genótipo Verona, enquanto os genótipos Sharon, Barcelona e Teresópolis Gigante foram os que menas atraíram.

Nas observações de atratividade (Tabelas 1 e 3) nota-se que as lagartas recém-eclodidas tiveram livre chance de escolha entre os discos foliares dos genótipos, podendo-se notar que elas apresentaram baixa mobilidade entre os discos, ou seja, a maioria das lagartas dirigiu-se aos discos de folhas e permaneceu neles durante o decorrer das avaliações, sugerindo que dentre os cariômonios, a atração tem participação importante na alimentação desses insetos. FANCELLI; VENDRAMIM (1993) também verificaram que lagartas recém-eclodidas de $A$. monuste orseis praticamente nãose movimentam, permanecendo no mesmo local onde é feita a postura.

Tabela 2 - Número médio ( \pm EP) de lagartas recém-eclodidas de P. xylostella nos intervalos de 10 a 30 minutos e de 10 minutos a 24 horas, obtidos em folhas de genótipos de couve-flor, em teste com e sem chance de escolha. Temperatura: $25 \pm 1^{\circ} \mathrm{C}$, UR: $70 \pm 10 \%$, fotofase: 12 horas.

\begin{tabular}{|c|c|c|}
\hline \multirow[t]{2}{*}{ Genótipos } & \multicolumn{2}{|c|}{$\underline{\text { Número médio de lagartas atraídas, em teste com chance de escolha }}$} \\
\hline & 10 a 30 minutos $^{2}$ & 10 minutos a 24 horas $^{3}$ \\
\hline Híbrido Barcelona & $11,2 \pm 1,54 \mathrm{a}^{1}$ & $4,2 \pm 0,54 \mathrm{a}$ \\
\hline Híbrido Piracicaba Precoce & $16,6 \pm 3,64 \mathrm{a}$ & $6,0 \pm 1,06$ a \\
\hline Híbrido Sharon & $15,8 \pm 3,81 \mathrm{a}$ & $5,9 \pm 1,17$ a \\
\hline Híbrido Silver Streak & $19,8 \pm 6,45 a$ & $7,2 \pm 2,24 \mathrm{a}$ \\
\hline Híbrido Verona & $10,6 \pm 3,45 a$ & $4,2 \pm 1,28 \mathrm{a}$ \\
\hline Teresópolis Gigante & $15,8 \pm 4,42 \mathrm{a}$ & $5,7 \pm 1,43 \mathrm{a}$ \\
\hline $\mathrm{F}$ & $0,71^{\mathrm{ns}}$ & $0,70^{\mathrm{ns}}$ \\
\hline C.V. $(\%)$ & 87,65 & 79,11 \\
\hline \multirow[t]{2}{*}{ Genótipos } & \multicolumn{2}{|c|}{ Número médio de lagartas atraídas, em teste sem chance de escolha } \\
\hline & 10 a 30 minutos $^{2}$ & 10 minutos a 24 horas $^{3}$ \\
\hline Híbrido Barcelona & $11,9 \pm 1,13 \mathrm{a}^{1}$ & $5,5 \pm 0,26 a$ \\
\hline Híbrido Piracicaba Precoce & $11,8 \pm 5,40 a$ & $5,4 \pm 0,21 \mathrm{a}$ \\
\hline Híbrido Sharon & $13,4 \pm 1,12 \mathrm{a}$ & $5,7 \pm 0,14 \mathrm{a}$ \\
\hline Híbrido Silver Streak & $14,2 \pm 1,61 \mathrm{a}$ & $5,9 \pm 0,29 a$ \\
\hline Híbrido Verona & $10,4 \pm 1,57 \mathrm{a}$ & $4,9 \pm 0,44 \mathrm{a}$ \\
\hline Teresópolis Gigante & $13,3 \pm 1,55 \mathrm{a}$ & $5,7 \pm 0,15 \mathrm{a}$ \\
\hline $\mathrm{F}$ & $1,00^{\mathrm{ns}}$ & $1,48^{\mathrm{ns}}$ \\
\hline C.V.(\%) & 35,09 & 15,32 \\
\hline
\end{tabular}

${ }^{1}$ Médias seguidas de mesma letra na coluna não diferem entre si pelo teste de Tukey, ao nível de $5 \%$ de probabilidade.

${ }^{2}$ Total de lagartas nas avaliações de 10, 15 e 30 minutos.

${ }^{3}$ Média do número de lagartas nas nove avaliações de atratividade. 
Não-preferência para alimentação de traça-das-crucíferas por genótipos de couve-flor.

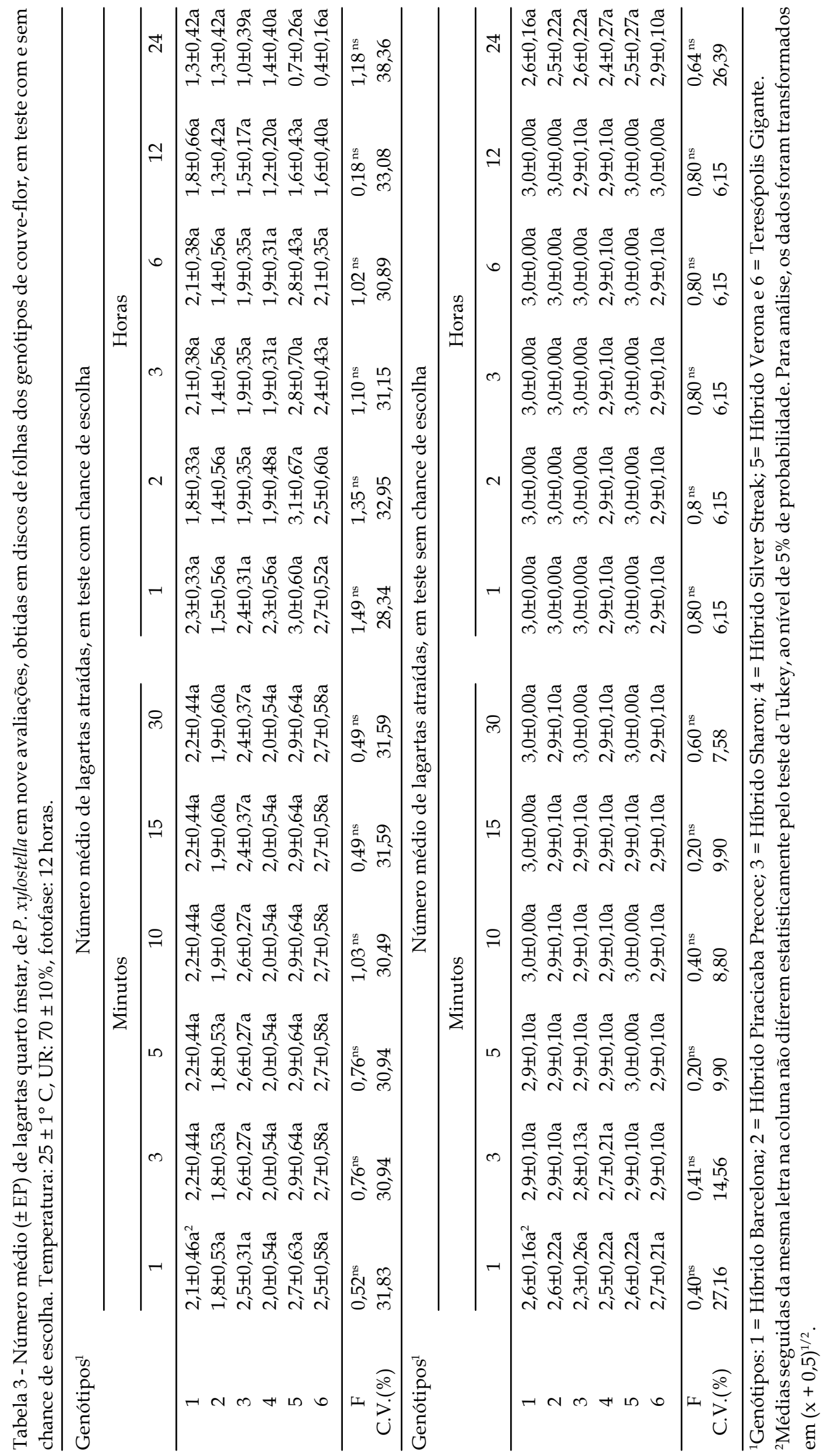


Tabela 4 - Número médio ( \pm EP) de lagartas quarto ínstar de $P$. xylostella nos intervalos de 1 a 30 minutos e de 1 minuto a 24 horas, obtidos em folhas de genótipos de couve-flor, em teste com e sem chance de escolha. Temperatura: $25 \pm 1^{\circ}$ C, UR: $70 \pm 10 \%$, fotofase: 12 horas.

\begin{tabular}{|c|c|c|}
\hline \multirow[t]{2}{*}{ Genótipos } & \multicolumn{2}{|c|}{ Número médio de lagartas atraídas (com chance) } \\
\hline & 1 a 30 minutos $^{2,3}$ & 1 minuto a 24 horas $^{4}$ \\
\hline Híbrido Barcelona & $13,1 \pm 2,66 \mathrm{a}^{1}$ & $2,0 \pm 0,29 \mathrm{a}$ \\
\hline Híbrido Piracicaba Precoce & $11,1 \pm 3,10 \mathrm{a}$ & $1,6 \pm 0,46 \mathrm{a}$ \\
\hline Híbrido Sharon & $15,1 \pm 1,61$ a & $2,1 \pm 0,23 \mathrm{a}$ \\
\hline Híbrido Silver Streak & $12,0 \pm 3,81 \mathrm{a}$ & $1,9 \pm 0,37 \mathrm{a}$ \\
\hline Híbrido Verona & $17,2 \pm 3,81$ a & $2,6 \pm 0,48$ a \\
\hline Teresópolis Gigante & $16,0 \pm 3,46 \mathrm{a}$ & $2,2 \pm 0,42 \mathrm{a}$ \\
\hline $\mathrm{F}$ & $0,60^{\mathrm{ns}}$ & $0,25^{\mathrm{ns}}$ \\
\hline C.V. $(\%)$ & 39,17 & 10,28 \\
\hline \multirow[t]{2}{*}{ Genótipos } & \multicolumn{2}{|c|}{ Número médio de lagartas atraídas (sem chance) } \\
\hline & 1 a 30 minutos $^{2}$ & 1 minuto a 24 horas $^{4}$ \\
\hline Híbrido Barcelona & $17,4 \pm 0,31 a^{1}$ & $2,9 \pm 0,03 \mathrm{a}$ \\
\hline Híbrido Piracicaba Precoce & $17,1 \pm 0,60 \mathrm{a}$ & $2,9 \pm 0,06 \mathrm{a}$ \\
\hline Híbrido Sharon & $16,8 \pm 0,51 \mathrm{a}$ & $2,9 \pm 0,07 \mathrm{a}$ \\
\hline Híbrido Silver Streak & $16,8 \pm 0,71 \mathrm{a}$ & $2,8 \pm 0,11$ a \\
\hline Híbrido Verona & $17,4 \pm 0,40 \mathrm{a}$ & $2,9 \pm 0,05 \mathrm{a}$ \\
\hline Teresópolis Gigante & $17,2 \pm 0,70 \mathrm{a}$ & $2,9 \pm 0,10 \mathrm{a}$ \\
\hline $\mathrm{F}$ & $0,25^{\mathrm{ns}}$ & $0,30^{\mathrm{ns}}$ \\
\hline C.V.(\%) & 10,28 & 8,17 \\
\hline
\end{tabular}

${ }^{1}$ Médias seguidas de mesma letra na coluna não diferem entre si pelo teste de Tukey, ao nível de $5 \%$ de probabilidade.

${ }^{2}$ Total de lagartas nas avaliações de 10, 15 e 30 minutos.

DDados originais foram transformados $(x+0,5)^{1 / 2}$.

${ }^{4}$ Média do número de lagartas nas nove avaliações de atratividade.

Tabela 5 - Massa seca média ( \pm EP) consumida $(\mathrm{mg})$ por lagartas recém-eclodidas e quarto ínstar de $P$. xylostella, em genótipos de couve-flor (30 dias do transplantio), em testes com e sem chance de escolha. Temperatura: $25 \pm 1^{\circ} \mathrm{C}, \mathrm{UR}$ : $70 \pm 10 \%$, fotofase: 12 horas.

\begin{tabular}{lcr}
\hline Genótipos & \multicolumn{2}{c}{ Massa seca consumida por lagartas recém-eclodidas } \\
\cline { 2 - 3 } & Com chance & Sem chance \\
\hline Híbrido Barcelona & $1,1 \pm 0,28 \mathrm{a}^{1}$ & $1,9 \pm 0,26 \mathrm{a}$ \\
Híbrido Piracicaba Precoce & $2,4 \pm 0,60 \mathrm{a}$ & $1,3 \pm 0,34 \mathrm{a}$ \\
Híbrido Sharon & $1,6 \pm 0,46 \mathrm{a}$ & $1,1 \pm 0,23 \mathrm{a}$ \\
Híbrido Silver Streak & $1,9 \pm 0,43 \mathrm{a}$ & $3,2 \pm 0,67 \mathrm{~b}$ \\
Híbrido Verona & $2,5 \pm 0,67 \mathrm{a}$ & $1,7 \pm 0,33 \mathrm{a}$ \\
Teresópolis Gigante & $2,0 \pm 0,37 \mathrm{a}$ & $1,4 \pm 0,25 \mathrm{a}$ \\
\hline F & $0,34^{\mathrm{ns}}$ & $4,76^{* *}$ \\
C.V.(\%) & 78,89 & 74,24 \\
\hline Genótipos & \multicolumn{1}{c}{ Massa seca consumida por lagartas de quarto ínstar } \\
\hline Híbrido Barcelona & Com chance & Sem chance \\
Híbrido Piracicaba Precoce & $9,7 \pm 2,34$ a & $10,2 \pm 0,70 \mathrm{a}$ \\
Híbrido Sharon & $8,9 \pm 2,49 \mathrm{a}$ & $8,5 \pm 0,52 \mathrm{a}$ \\
Híbrido Silver Streak & $10,1 \pm 0,67 \mathrm{a}$ & $8,2 \pm 0,73 \mathrm{a}$ \\
Híbrido Verona & $8,5 \pm 1,29 \mathrm{a}$ & $8,5 \pm 0,51 \mathrm{a}$ \\
Teresópolis Gigante & $11,0 \pm 2,21 \mathrm{a}$ & $8,3 \pm 0,57 \mathrm{a}$ \\
\hline F & $11,2 \pm 2,05 \mathrm{a}$ & $8,9 \pm 0,84 \mathrm{a}$ \\
C.V.(\%) & $0,34^{\mathrm{ns}}$ & $1,31^{\mathrm{ns}}$
\end{tabular}

${ }^{1}$ Médias seguidas de mesma letra na coluna não diferem entre si pelo teste de Tukey, ao nível de $5 \%$ de probabilidade. 
Os dados de massa seca consumida nos testes com e sem chance de escolha, para lagartas recém-eclodidas de P.xylostella (Tabela 5), revelaram diferença significativa entre os genótipos apenas no teste sem chance de escolha, destacando-se o híbrido Silver Streak como o mais preferido para alimentação $(3,27 \mathrm{mg})$, enquanto o híbrido Barcelona foi um dos menos consumido $(1,08$ $\mathrm{mg}$ ), sendoqueestemesmo material tambémapresentou tendência de menor consumo no teste com chance de escolha (1,10 mg). Em ensaio com e sem chance de escolha, a alimentação do inseto determina sua preferência entre os genótipos testados, sendo que as medidas de dano por alimentação é a mais adequada na obtenção de genótipos resistentes (SMITH et al., 1994), uma vez que os objetivos principais dos programas de melhoramento da cultura são promover danos reduzidos às plantas e aumento na produtividade qualidade.

Os dados relativos à massa seca consumida em testes com e sem chance de escolha para lagartas de quarto ínstar (Tabela 5) mostraram que, embora não tenha havido diferença significativa entre os genótipos, verifica-se uma tendência de menor consumo da lagarta nos híbridos Silver Streak $(8,48 \mathrm{mg})$ e Sharon $(8,20$ $\mathrm{mg}$ ) nos testes com esem chance de escolha respectivamente, sugerindo serem menos preferidos pelos insetos. Segundo Oliveira et al. (2004), lagartas de A.monuste orseis também não apresentaram diferença no consumo sobre esses mesmos genótipos de couve-flor.

\section{CONCLUSÕES}

- Os genótipos de couve-flor testados não influenciaram a atratividade das lagartas recém-eclodidas (primeiro ínstar) e 4o ínstar.

- Os genótipos estudados não apresentam resistência do tipo não-preferência para alimentação por lagartas de P. xylostella.

\section{AGRADECIMENTO}

À Capes pela concessão de bolsa de mestrado ao segundo autor e ao CNPq pela concessão de bolsa de produtividade em pesquisa ao primeiro autor.

\section{REFERÊNCIAS}

ALMEIDA, K. Comportamento de cultivares de couve-flor sob sistema de plantio direto e convencional em fase de conversão ao sistema orgânico. 2004. 55p. Dissertação (Mestrado) - Universidade Federal de Lavras, Lavras, 2004.

CAMARGO, L.S. As hortaliças e seu cultivo. São Paulo: Fundação Cargill, 1992. 252p.

DIAS, D.G.S.; SOARES, C.M.S.; MONNERAT, R.G. Avaliação larvicida de origem microbiana no controle de traça-das-crucíferas em couve-flor no Distrito Federal. Brasília: Embrapa Hortaliça, 2002. 4p. (Comunicado Técnico).

FANCELLI, M.; VENDRAMIM, J.D. Não-preferência para alimentação e oviposição de Ascia monuste orseis (Godart) (Lepidoptera: Pieridae) em cultivares de couve. Anais da Sociedade Entomológica do Brasil, v.22, p.232-237, 1993.

FILGUEIRA, F.A.R. Manual de olericultura: cultura e comercialização de hortaliças. São Paulo: Ed. Agronômica Ceres, 1982. v.2, 357p.

LARA, F.M. Princípios de resistência de plantas a insetos. 2. ed. São Paulo: Ícone, 1991. 336p.

OLIVEIRA, C.N.; BOIÇA JUNIOR, A.L.; ANGELINI, M.R. Não-preferência para alimentação de Ascia monuste orseis (Latreille, 1819) (Lepidoptera: Pieridae) por genótipos de couve-flor. In: CONGRESSO BRASILEIRO DE ENTOMOLOGIA, 20., Gramado. Resumos. Gramado: Sociedade Entomológica do Brasil, 2004. p.589.

SANTOS, M.A.T. Caracterização química das folhas de brócolis e couve-flor (Brassica oleracea L.) para utilização na alimentação humana. 2000. 96p. Dissertação

(Mestrado) - Universidade Federal de Lavras, Lavras, 2000.

SMITH, C.M.; KHAN, Z.R.; PATHAK, M.D. Techniques for evaluating insect resistance in crop plants. Boca Raton: CRC PRESS, 1994. 320p.

TORRES, A.L. Efeito de cultivares de repolho e extratos aquosos vegetais na biologia de Plutella xylostella (L.) e no parasitóide Oommyzus sokolowskii (Kudjumov). 2004. 109p. Tese (Doutorado) - Faculdade de Ciências Agrárias e Veterinárias, Universidade Estadual Paulista, Jaboticabal, 2004.

Recebido em 3/3/08

Aceito em 15/5/09 